\title{
A COMUNICAÇÃO DE TENDÊNCIAS DE MODA EM REDE ON-LINE
}

\author{
Amanda Queiroz Campos* \\ Richard Perassi Luiz de Sousa* \\ Luiz Salomão Ribas Gomez
}

\begin{abstract}
RESUMO: O cenário de convergência entre as telecomunicações e a informática conecta o mundo inteiro. Assim, configura-se a chamada sociedade em rede, promovendo outras dinâmicas comunicacionais e configurando novas relações de espaço-tempo. Inseridos neste contexto de mudança dos processos de comunicação, as empresas de pesquisa de tendências e direcionamento para produtos podem contar com suportes e canais midiáticos, que configuram uma nova realidade para a coleta e a distribuição de informações. Este texto propõe relacionar de maneira crítica as considerações acerca do modo como são veiculadas, em rede on-line, as informações de tendências direcionadas aos produtos de moda. Considera-se mais especificamente o web sítio MudPie D Click, para exemplificar a mudança dos suportes trendbooks ou cadernos de tendências, cujas versões impressas são substituídas por versões digitais, divulgadas em rede on-line.
\end{abstract}

PALAVRAS-CHAVE: Tendências, Sociedade em rede, Website.

\section{Introdução}

A comunicação é um fenômeno social capaz de transformar realidades. Em meio digital, a comunicação amplia seu poder de transformação, causando forte impacto entre o público usuário de computadores ou outros aparelhos digitais interligados em rede. Isso repercute em toda a sociedade porque, em geral, os formadores de opinião dispõem de acesso à mídia on-line suportada por tecnologia digital. Desse modo, o domínio da composição e operacionalidade dos processos comunicativos e de informação em meio digital implica significativamente na definição dos parâmetros de relevância e dos objetivos comunicacionais de profissionais e organizações especificas, como as que são relacionadas à moda.

Cada mídia desenvolve uma cultura própria, cuja sintaxe interfere no conteúdo final das mensagens que veicula. Portanto, a escolha ou a determinação do canal de mediação não é isenta de consequências e deve ser considerada de acordo

\footnotetext{
*Universidade Federal de Santa Catarina. Imeio: amandaqc88@ gmail.com.

* Universidade Federal de Santa Catarina. Imeio: richard.perassi@uol.com.br.

*Universidade Federal de Santa Catarina. Imeio: salodesigner@gmail.com.
} 
com os interesses do emissor e dos receptores. Para Charaudeau (2009, p. 39) "comunicar, informar, tudo é escolha. Não somente escolha de conteúdos a transmitir, não somente escolha das formas adequadas".

A afirmação implica que signos e códigos sempre estão presentes nos processos comunicativos e que todo o sistema de comunicação é também impulsionado por sistemas de ligações que se completam em diversas situações e adequadamente à nossa percepção. Já que, além dos signos, signifcados, decodificações entre locutor e ouvinte, "todo o ato de comunicar tem a sua dimensão sociocultural".

Ainda, nos processos comunicativos, devem ser considerados os valores propostos e impostos pela própria mídia, uma vez que, nas palavras de McLuhan, o meio é a mensagem (McLUHAN, FIORE, 1967).

O cenário informatizado de convergência das telecomunicações apresenta uma abrangência global e configura a "sociedade em rede", promovendo outras dinâmicas comunicacionais e configurações espaço-temporais (CASTELLS, 2002). No campo da moda, juntamente a outras mudanças, isso alterou os processos de tratamento da comunicação dos trendbooks ou cadernos de tendências que, atualmente, são disponibilizados em plataformas on-line e veiculados na rede, em contraposição às tradicionais versões impressas.

O web sítio de tendências de moda MudPie (<www.mpdclick.com>) é aqui apresentado como exemplo, pois caracteriza-se como um sítio virtual sustentado por plataforma digital, podendo ser acessado on-line via rede, por meio da internet.

\section{Metodologia}

A pesquisa é caracterizada como "descritiva", porque "observa, registra, correlaciona e descreve fatos ou fenômenos de uma determinada realidade sem manipulá-los" (VERGARA, 2006). Além da literatura sobre o tema, que é indicada 
como fonte secundária, há também o acesso a fontes primárias, como documentos e registros disponíveis no website MudPieDClick.

As etapas de pesquisa foram as seguintes:

- Estudos exploratórios para reconhecimento inicial do fenômeno estudado;

- Estudos teóricos, visando apreender os temas em estudo em seu contexto cultural;

- Utilização da referência teórica para coletar informações na realidade observada;

- Levantamento de informações no sítio digital, como parte da realidade observada.

- Seleção, organização e interpretação das informações.

\section{Relação emissor-receptor no processo de veiculação}

Vive-se,desde o início do século XXI, um processo de transição no que tange os processos de comunicação, novas tecnologias e a revolução das mídias. De acordo com autor $(X)$, é comum que nesse período surjam certezas e incertezas em relação aos fenômenos de comunicação e (in)comunicação. As novas tecnologias, a velocidade da informação e o processo comunicacional trazem um cenario mais complexo e precisam de respostas também mais complexas em função ao modelo emissor-receptor.

Segundo Pereira (2008, p.20), os estudos sobre a retórica datam do século III A.C e tiveram como pesquisador primeiro, Aristóteles. Esses estudos ressaltavam a transmissão da informação como processo persuasivo. Ainda os estudos sistematizam a transmissão da informação através da sua divisão em três elementos básicos: locutor, discurso e ouvinte. Em que o locutor é aquele que transmite a mensagem; o discurso consiste no que é dito; e o ouvinte é a quem a 
mensagem se desitna, a audiência.

Esse modelo linear clássico e tricotômico desenvolvido pro Aristóteles persiste até a contemporaneidade, mas torna-se incompleto por ignorar ruídos e as especificades culturais que formam o repertório de cada locutor e de cada ouvinte, sem enfatizar o papel central dos sujeitos no processo. Por sua vez, estudos menos remotos da informação destinam-se à análise de significados e mensagens nas culturas, sua produção e troca de significados (MELO, 1998).

O modelo de Eco Fabbri et. al. (1965) considera que no processo de comunicação, a mensagem deve ser compreendida como forma significante, podendo ser preenchida por diversos significados. Isso, desde que os códigos utilizados para compor e interpretar as mensagens deem conta de estabelecer relações específicas entre os significantes e os significados. O que considera que emissores e destinatários incidem sobre os processos de codificação e decodificação, inserindo novas informações às mensagens (ECO, FABBRI et al.1965).

\section{A flexibilidade como característica básica da sociedade da informação}

Borges (2005) destacou a relevância da concepção e desenvolvimento dos meios de comunicação para a prospecção de novos modos de ação e interação interpessoal. O autor reitera como o progresso resultante de pesquisas e inovações tecnológico-digitais revolucionou a comunicação humana. Além disso, os meios de comunicação de massa são apresentados como sistemas de comunicação monológicos, caracterizados pela disseminação de formas simbólicas, as quais são projetadas e produzidas para alcançar um número significativo e indefinido de receptores.

Por outro lado, considerando a hipermídia interativa, Barreto (1998) afiança que a interação torna possível a participação ativa das pessoas na fluida correnteza de informações. Desse modo, o usuário interage com esse fluxo de dados de forma direta, conversacional e flexível. Essa interação ocorre em tempo real, através de 
conexão on-line em rede, ampliando o espaço de comunicação e suas possibilidades. Pois, de acordo com os intuitos dos usuários, há o acesso a qualquer tempo aos diferentes repositórios de informação.

A flexibilidade se estabelece como base do novo paradigma da informação, favorecendo a ideia de "aprendizagem", uma vez que todo o sistema se mostra plástico, de fácil reconfiguração, e disponível para assimilar e incorporar mudanças (WERTHEIN, 2000). A flexibilidade é, portanto, o aspecto determinante da sociedade da informação, indicando a perspectiva de ininterrupto aperfeiçoamento intelectual e técnico, porque o paradigma da informação "imprimiu uma nova dinâmica na forma de geração e aquisição do conhecimento e mudanças nas relações entre conhecimento tácito e codificado" (LEMOS, 1999. p.130).

A influência dessa característica flexível da sociedade da informação é percebida em diversas áreas e ambientes, alcançando e alterando, tanto a dinâmica do mercado quanto das instituições de ensino superior (IES). A coleta de dados e informações é uma estratégia das organizações, institucionais ou empresariais, que buscam produzir conhecimento sobre a sociedade e o mercado, aplicando-o no processo de constante inovação.

Cada vez mais a coleta e a disseminação de dados e informações ocorre através da rede on-line. Há uma profusão diversificada de dados, impondo a necessidade de constantes mapeamentos transversais, tendo em vista os diversos ambientes ou setores da cultura global. No caso das organizações empresariais, como as empresas da moda, a coleta de informações serve para o reconhecimento da evolução das características do mercado e do seu público foco, propiciando a construção de cenários atuais e a prospecção de tendências futuras.

\section{A internet como veículo de moda}

Por suas características, como sistema que permite a navegação na rede, a internet pode ser percebida como mídia de massa e ferramenta de busca. $O$ 
caráter de massa se estabelece porque milhões de pessoas navegam através da internet. Porém, o processo interativo de navegação, os sistemas de busca e o uso de palavras ou expressões-chave permitem a prévia seleção individualizada de temas e ambientes de interesse. Assim, apesar de estar conectado em uma mídia de massa, o usuário pode permanecer períodos de longa duração estudando um único tema e frequentando um único conjunto de sítios especializados.

A mídia eletrônica tradicional só se aproximou disso quando ofereceu estações ou canais de temas específicos. Porém, enquanto não houver a popularização e a consolidação de rádio e televisão digital-interativos, o número de estações especializadas que as rádios e as televisões ainda será diminuto diante da quantidade oferecida na internet.

Há o notável crescimento da rede navegável pela internet, ampliando a diversidade temática e, também, a quantidade de sítios que tratam de um mesmo tema. Porém, isso implica na necessidade de adaptações ou de melhores soluções e tecnologias para a navegação e a busca qualificada via internet. Isso implica também no aprimoramento pessoal dos usuários, com aprendizado para o uso de plataformas e programas auxiliares e para o desenvolvimento de soluções particulares, as qualificam sua navegação.

O crescimento da rede também se mostra pródigo na proliferação de sítios e disponibilização de conteúdos sobre moda. Hinerasky (2006) assinala a quantidade de portais sites e blogs especializados no assunto que tratam do tema sob diversos enfoques Outros estudos publicados tratam das redes sociais, Orkut, Facebook e Twitter, como espaços de disseminação de dados e informações sobre estilos e comportamentos relacionados à moda.

A palavra blog é a forma reduzida de weblog, indicando espaços virtuais que permitem o registro frequente de informações. Muitos blogs são compostos e dispostos como diários pessoais. Entretanto, outros são constantemente atualizados com conteúdos específicos, caracterizando-se como ambiente de notícias ou de estudos. Uma das vantagens dos blogs é permitir que os usuários 
publiquem seu conteúdo sem conhecimento técnico especializado. Outros aspectos de uso que caracterizam os blogs são: (1) liberdade do indivíduo quanto à forma de expressão, (2) a facilidade de comunicação em grupo, (3) o contato entre pessoas ao redor do mundo e a multiplicidade de autores (HANSEN e BEHLING, 2010).

Há estudos que tratam sobre elaboração de estratégias de comunicação e marketing, voltadas para as áreas de Design e Moda, a partir de informações veiculadas em blogs. O ponto de partida é determinado pelo conjunto dos processos colaborativos e de construção coletiva, que disponibilizam informações pessoais referentes aos hábitos e modos de vida de pessoas comuns. As marcas também utilizam os blogs como fonte de coleta de dados, para otimizar o processo de posicionamento e comunicação da marca, diante do seu públicofoco.

A internet também é objeto de estudo nas pesquisas que avaliam os processos como as informações de moda são encontradas e interpretadas na rede. Neste caso, o ponto de partida é a perspectiva do usuário e sua interação com a interface gráfico-digital (Fig. 1), tendo em vista as características do design gráfico e do design de informação, pois é o design de informação que suporta a expressividade e a significação da mensagem gráfica. É descrito e interpretado a disposição das informações e sua participação no processo de comunicação e aprendizagem. 


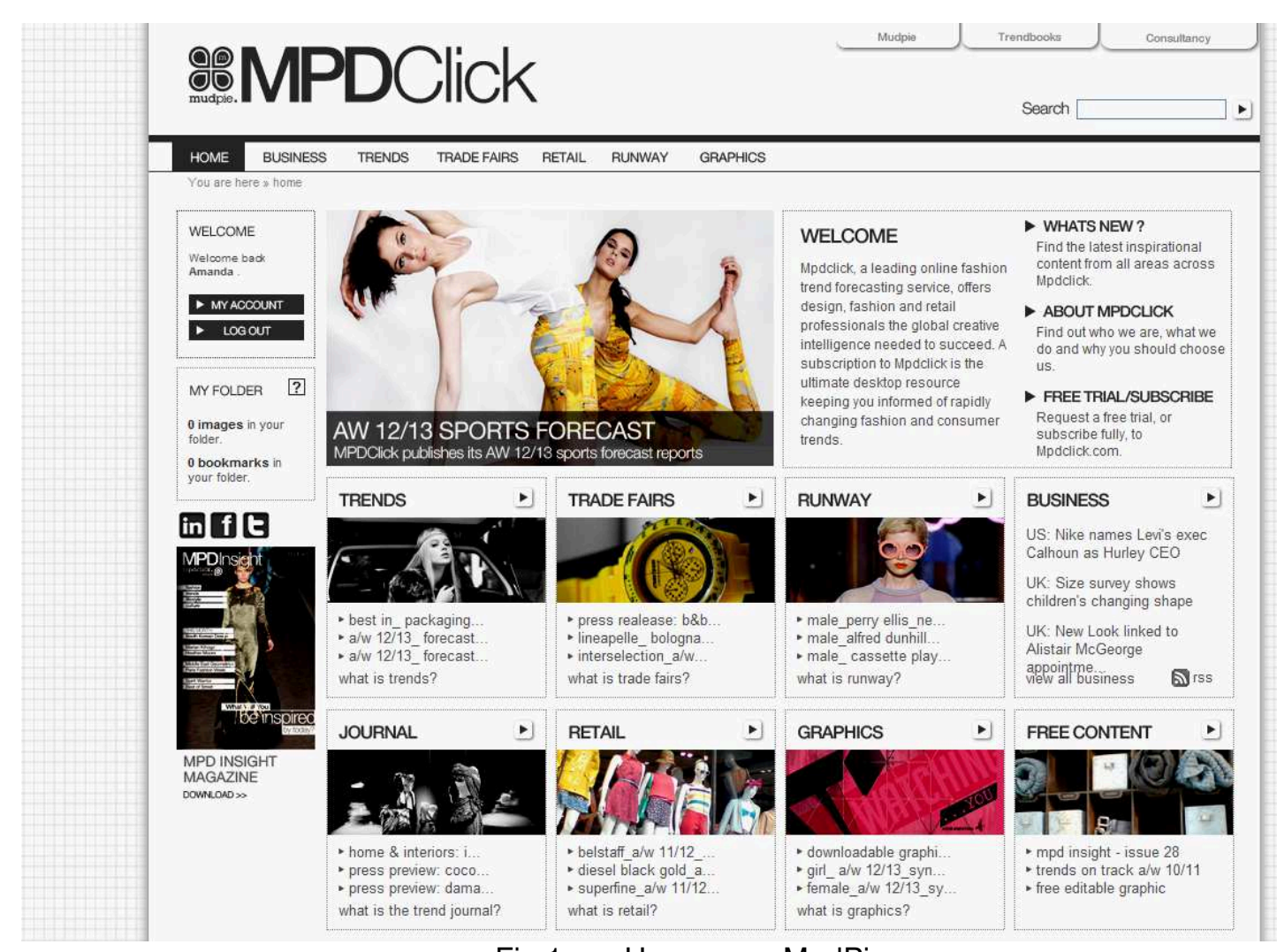

Fig 1ura: Homepage MudPie.

\section{O sítio de moda MPDClick}

A interface gráfica do sítio MudPie $D$ Click é sustentada por uma plataforma digital on-line, apresentando-se primeiramente como uma página principal (Fig. 1) que, além das informações ali divulgadas, oferece diversos links que direcionam o usuário para outras páginas do mesmo sítio ou para outros sítios relacionados.

O emissor do sítio é a empresa britânica Mud Pie Fashion Forcasting, que foi fundada por Fiona Jenvey, empresária que se mantém como CEO da organização há 19 anos. A principal atividade da empresa é a pesquisa de tendências da moda, considerando sua experiência nos mercados de moda adulto, jovem e infantil. Além disso, a empresa presta consultoria ao mercado, oferecendo serviços para auxiliar empresas de produtos de moda a desenvolver suas coleções de acordo com as tendências prospectadas. 
As consultorias são desenvolvidas sob a marca MudPie Consultancy, que propõe soluções específicas do design, de acordo com as atuais tendências e com as necessidades e desejos dos consumidores. Esses desejos e tendências são considerados desde o desenvolvimento das escalas de cores, passando por conceitos e temáticas, indo até a arte-finalização dos produtos.

A empresa dispõe de uma respeitável equipe com designers e analistas de tendências, oriundos de diferentes nacionalidades, para aplicar seu conhecimento sobre as tendências em produtos e serviços. A sua rede ou network de trabalhadores se estende por 50 países. Além da sede no Reino Unido, atua por meio de escritórios em países como: Austrália, Brasil, Tailândia e Estados Unidos.

Além de manter a plataforma on-line para a comunicação de tendências, a empresa oferece vetores gráficos e estampas e, ainda, desenvolve e oferece ao mercado trendbooks ou cadernos de tendências de moda, com cores, formas, estampas e gráficos e uma mídia em DVD com vetores artísticos modificáveis, Segundo a empresa. é oferecida "uma solução completa" (MUDPIE, 2011). Os cadernos são vendidos em mais de cinquenta países, oferecendo a estilistas e designers ideias para o desenvolvimento de coleções de produtos, de acordo com os ciclos das estações que determina o mercado da moda.

Mud Pie D Click ou MPDClick é o nome do serviço on-line de pesquisa de tendências e direcionamento comercial para moda. O serviço propõe oferecer inspiração criativa e inteligência advindas do consumidor e que são necessárias para o sucesso de estilistas, designers, compradores e executivos da moda em todo o mundo. A assinatura do sítio permite que os profissionais se informem rapidamente sobre as mudanças da moda e as tendências de consumo, oferecendo ainda conteúdo de inspiração, pesquisa de mercado e uma livraria de recursos gráficos.

Os dados coletados na internet indicam que acesso a informações e serviços do sítio Mud Pie D Click é viabilizado por meio de assinatura. O valor anual da assinatura é de US \$3.375,00 (três mil trezentos e setenta e cinco dólares) por usuário, sendo que a opção para até cinco usuários, denominada de corporate 
click, custa US $\$ 6.000,00$ (seis mil dólares anuais). Contudo, os preços são compatíveis com o mercado, tendo em vista que a empresa brasileira UseFashion cobra $R \$ 2.580,00$ (dois mil quinhentos e oitenta reais) para oferecer livre acesso às suas informações, e a empresa líder desse mercado, Worth Global Style Network (WGSN), cobra US $\$ 12.000,00$ (doze mil dólares) para oferecer senha de acesso para um usuário. Esses valores indicam o alto custo que o mercado se dispõe a pagar por informações e conhecimentos relacionados aos negócios da moda.

A assinatura dá direito de acesso à reportagens e relatórios textuais e fotográficos em profundidade acerca das tendências globais da moda, tendências em cores, novidades e notícias da indústria criativa e da moda, especificamente, feiras de tendência e de produtos, destinos de varejo de moda, informações e análises dos principais desfiles e eventos de moda, influências culturais nas tendências e na moda, além de acesso à uma livraria própria de gráficos, estampas e formas de produtos do vestuário passíveis de download. O conteúdo oferecido é dividido em seis seções:

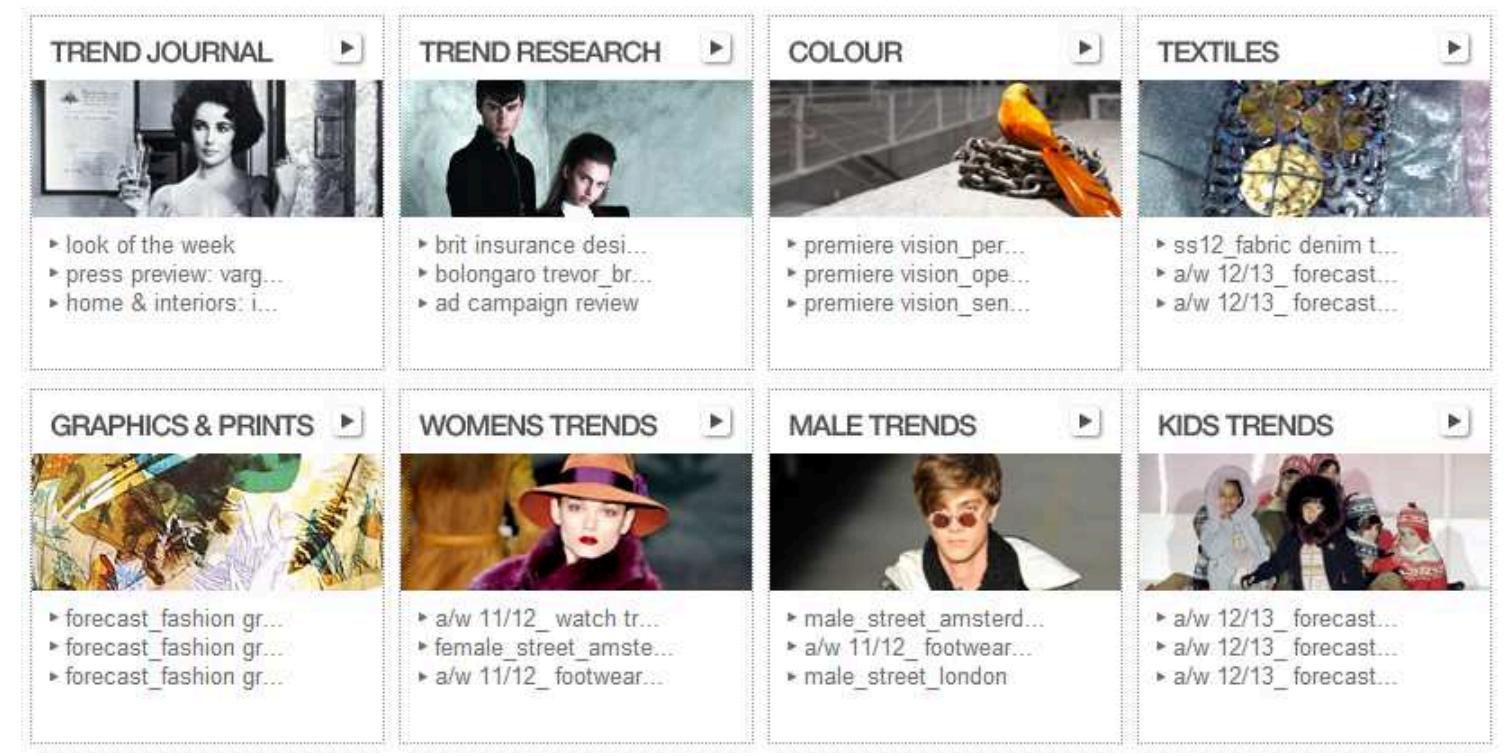

Figura: opções links de conteúdo para navegação em trends.

1. businesses (empresas), área cujo conteúdo é composto por novas tendências 
de carreira e negócios ou informações de mercado. São fornecidos notícias das indústrias têxteis e de confecção, com insights sobre comportamento de consumo e inteligência estratégica e reportagens focadas no varejo global e nos modos intuitivos para compreender a modelagem das indústrias criativas em geral.

2. trends (tendências) é um diretório dedicado à observação de diversas tendências, prospecções e relatórios sobre diversas áreas da indústria da moda. A área das tendências é beneficiada por uma navegação simplificada e um arquivo extenso de conteúdos que, anteriormente, são apresentadas como links na página principal (Fig. 2). A simplificação decorre da categorização específica por área da indústria, permitindo de modo efetivo e rápido a localização de informações (MUDPIE, 2011).

3. trade fairs (feiras de tendências) é a área do sítio que traz informações sobre as principais feiras de tendências e produtos relacionadas ao universo da moda. Nem sempre as empresas e profissionais assinantes têm a possibilidade de atender aos eventos de varejo e tendências de moda que ocorrem ao redor do mundo, seja por questões financeiras ou impossibilidade de tempo, às vezes, seja pela falta um profissional especializado em coletar e analisar as informações provenientes desse tipo de exibições e exposições. Além disso, são lançados relatórios especiais de cada uma das feiras com direcionamentos para público feminino ou masculino, sobre carreiras e tendências contemporâneas.

4. retail (varejo) é a seção que oferece dados sobre tendências de consumo de cidades em todo o mundo. As informações são passadas por meio de dossiês documentais fotográficos, análise de tendências de vestuário e acessórios e, também, reportagens especiais de coolhunting e direcionamentos para as estações de moda (primavera-verão e outono-inverno), além de relatórios mensais de tendências de varejo (retail trends). A seção oferece ainda relatório e reportagens sobre visual merchandising ou vitrinismo, trazendo ideias inspiradoras para displays e exposição de produtos no interior da loja e na vitrine. A aba retail, localizada no menu principal, ainda oferece navegação seguindo os links retail home - varejo para casa e interiores; female; male; kids; retail trends; merchandising and interiors; city guides e all reports. Em cityguides ou guia de 
cidades, pode-se acessar 17 cidades "de moda" com conteúdo especial. Esse conteúdo engloba histórico da cidade, mapa interativo, links interessantes e fotos, apresentando um diretório para navegação com conteúdo específico para profissionais de moda.

5. runway (passarela) é o principal conteúdo exposto e diz respeito à filtragem de imagens dos principais desfiles referentes às estações da moda, com a cobertura das maiores semanas de moda do mundo. Na seção runway calendar estão dispostos, em forma de lista, uma série de desfiles de moda que tiveram a cobertura da equipe de profissionais MudPie.

6. graphics (gráficos) é a área que corresponde à uma biblioteca de gráficos disponível em tempo integral. O sítio compara a biblioteca de gráficos com uma equipe de designers "the Graphics area is like having your own in-house design team, available 24/7'. A seção oferece 25 pacotes individuais de gráficos de tendência a cada semana, para serem "baixados" (download) e editados, caso sejam de interesse do responsável pela equipe criativa.

\section{As informações de moda em contexto hipermidiático}

$\mathrm{Na}$ sociedade da informação, a estrutura linear da comunicação para obtenção de informações é substituída por uma estrutura associativa. Isso se dá na condição de um hipertexto multimidiático. O texto hipermídia possibilita a comunicação da informação em diversas linguagens: escrituras, imagens e sons, que são compostas de modo combinado.

Apesar da profusão de conteúdos oferecidos, o sítio on-line MudPieDClick estrutura-se de modo bem organizado, por meio de caixas e blocos com grupos de informação. Sob fundo claro, apresentando tipografia visível e simplificada, o layout da interface gráfico-digital é considerada clean. A utilização apenas de escalas monocromáticas em tons acinzentados e brancos possibilita que os recursos imagéticos coloridos, como vetores e fotografias coloridas de alto contraste e resolução, sobressaiam como foco informativo e comunicativo, sem interferências ou ruídos visuais do background. 
A navegação propõe interatividade no processo de comunicação e aprendizado das tendências de moda, possibilitando a coleta de material para inspiração. A plataforma possibilita direcionamentos por trend reports para sítios com informações semelhantes ou complementares, além de carregar revistas eletrônicas com dados relevantes para o reforço do conteúdo apresentado. A organização visual aponta para uma navegação ágil, permitindo o rápido acesso ao conteúdo desejado. As diversas páginas são linkadas e a ordenação é apenas conceitual, permitindo atalhos de direcionamento direto do usuário para a página de seu interesse.

A hipermídia vem substituindo com mais agilidade e componentes lúdicointerativos a forte tradição dos trendbooks ou cadernos de moda impressos. Porém, o suporte digital ainda é ocupado por materiais que não possibilitam a intervenção ou interação do usuário, configurando-se mera transposição sem adaptação ou progresso do meio impresso para o meio digital. Isso é notório nos trendboards (pranchas de tendências) e nos trend reports (relatórios de tendências), que aparecem no sítio MPDClick em formato de imagem estática, diante de diversas possibilidades e artifícios hipermidiáticos para a otimização desses produtos.

Nos casos assinalados no item anterior (O sítio de moda MPDClick) faltou inserir nos produtos a flexibilidade ou a plasticidade que caracteriza a sociedade da informação, pois os diversos modos midiáticos, quando bem resolvidos, trabalham conjuntamente para produzir sentido, motivação e permitir a criação de novas possibilidades. Como foi dito anteriormente, é a flexibilidade da mídia e sua interação com o usuário que possibilitam a constante recriação das mensagens, da mídia e do próprio usuário. Pois, esse necessita conhecer tendências e desenvolver sua criatividade, transformando-se em resposta às novidades de mercado para continuar alimentando a dinâmica efêmera da sociedade de consumo.

É interessante também propor uma reflexão em relação ao usuário do sítio de tendências, visto que, os ambientes digitais de informação e conhecimento na rede on-line contribuem para desenvolvimento de "um novo usuário, navegante 
em redes de informática, que reintroduz o poder da escrita vinculado à imagem, fortalecendo as possibilidades de um novo tipo de interação" (CARVALHO, 2006, p. 9). Assim, o usuário, já adaptado aos sistemas interativos, depara-se com uma interface pouco propícia para a interação.

Atualmente as pesquisas para desenvolvimento de softwares e interfaces estão centradas no indivíduo.Ou seja, iniciam de perspectivas cognitivas com o objetivo de interpretar as necessidades de informação intelectuais e sociológicas dos usuários.

Quanto aos usuários, esta nova abordagem concebe os indivíduos como pessoas com necessidades cognitivas, afetivas e fisiológicas fundamentais próprias que operam dentro de esquemas que são partes de um ambiente com restrições socioculturais, políticas e econômicas. Essas necessidades próprias, os esquemas e o ambiente formam a base do contexto do comportamento de busca de informação (FERREIRA, 1995, p.6).

Borges (2005) coloca que a interatividade aplicada à comunicação implica a presença de emissores e receptores sem distinção de importância, o que pressupõe uma relação dialógica para a troca da informação. Desse modo, para o autor, a internet beneficiou organizações, sociedade e sistemas de trocas com a perspectiva de fecundidade mútua. Porém, apesar de todo o investimento e desenvolvimento, a plena interação entre emissor e receptor ainda não ocorre de modo pleno nos sítios de tendências de moda.

As intervenções dos usuários podem ser perigosas, porque podem deturpar as informações criteriosas que foram disponibilizadas pelo emissor. Entretanto, propõe-se maior liberdade para o usuário recriar as informações em suporte próprio, possuindo proteções que impossibilitem a alteração da informação original Para tanto, é necessária uma melhor adaptação dos discursos impressos tradicionais à plataforma hipermídia.

Destacam-se, nas atuais condições contemporâneas da web, as condições que oportunizam ao usuário reorganizar as informações ou enriquecer os conteúdos, 
por meio de comentários, avaliações e personalizações. Isso poderia ser indicado como possibilidade para transformar as informações de tendências de moda em rede on-line que, ainda, se assemelham aos trendbooks ou cadernos de moda impressos, oportunizando a adaptação criativa das práticas tradicionais à hipermídia.

Outra característica relevante de parte dos conteúdos editorias de moda veiculados na internet é a sua gratuidade (ORLANDI, 2000). Porém, isso é incompatível com a natureza comercial do sítio MudPieDClick, cujo acesso é restrito aos assinantes, mediante a pagamento de valor elevado pela assinatura. Entretanto, além de não oferecer gratuitamente o seu conteúdo, o sítio não aproveita a oportunidade de receber informação gratuita advinda dos usuários.

\section{Considerações finais}

O desafio no mundo da moda é a melhor utilização da hipermídia para a veiculação de conteúdos específicos. No exemplo estudado, observou-se a organização de tendências com foco em empresas da moda. O contexto hipermidiático implica que canais multimídia utilizados de forma interativa, conjugada e complementar, porque as diversas fontes de informação influenciam diretamente nos conteúdos e também no comportamento sócio-cultural dos usuários.

De modo geral, há uma convivência compartilhada e complementar nos processos de disseminação da informação e do conhecimento de tendências de moda veiculados em meios tradicionais, trendbooks ou cadernos de moda impressos, ou em hipermídia suportada por plataformas digitais on-line. Entretanto, há ainda um caminho a percorrer no processo de transição eficiente da informação de moda do meio impresso para a hipermídia, pois essa última não foi explorada e desenvolvida em toda sua potencialidade, especialmente, com relação à flexibilização de parte dos produtos oferecidos, para que se possa permitir e usufruir os aspectos positivos da plena interatividade. 


\title{
Agradecimento
}

Cabe-nos um agradecimento à equipe brasileira de vendas do websítio MPDClick que liberou $o$ acesso livre para a pesquisa com fins acadêmicos.

\section{THE ONLINE COMMUNICATION OF FASHION TRENDS}

\begin{abstract}
The scenario of convergence between telecommunications and informatics connects the world. It sets up the call the network society, promoting communication and other dynamics by setting new relations of space-time. Included in this changing context of communication processes, businesses of trend research can count on media and media channels, which shape a new reality for the collection and distribution of information. This paper proposes to critically build remarks on the way the information of fashion trends are conveyed online. The paper considers specifically the website Mudpie D Click to exemplify the changing of supports in the broadcast of trendbooks, whose print versions are replaced by digital versions, published in online networks.
\end{abstract}

KEYWORDS: Trends, Network society, Website.

\section{REFERÊNCIAS:}

AMARAL, Adriana. AQUINO, Maria Clara Aquino. MONTARDO, Sandra Portella. (orgs). INTERCOM Sul 2010: Perspectivas da pesquisa em comunicação digital. São Paulo: INTERCOM, 2010.

AMARAL, Adriana; RECUERO, Raquel e MONTARDO, Sandra. (orgs). Blogs.Com: estudos sobre blogs e comunicação. São Paulo: Momento Editorial, 2009.

BARRETO, Aldo de Albuquerque. Mudança estrutural no fluxo do conhecimento: a comunicação eletrônica. Ciência da Informação. Brasília, v. 27, n.2, 1998.

BORGES, Admir Roberto. A propaganda na vazante da "infomaré". Congresso Brasileiro de Ciências da Comunicação. XXVIII INTERCOM, 05 a 09 de setembro de 2005. Rio de Janeiro.

CASTELLS, Manuel. A Sociedade em Rede. Lisboa: Fundação Calouste Gulbenkian, 2002.

CHARAUDEAU, Patrick. Discurso das mídias, São Paulo: Editora Contexto, 2006.

COBRA, Marcos. Marketing \& Moda. Senac São Paulo: Cobra Editora e Marketing, 2007. 
CORREA, Mychelle Jacob. Gêneros digitais: as plataformas de comunicação e as novas mídias no marketing de Moda. Mercatus Digital, Recife, v. 1, n. 1, p. 5768, julho de 2010.

ECO, Umberto. FABBRI, P. et al. Prima proposta per un progetto di ricerca interdisciplinare sul rapporto televisione/pubblico. Perugia: Istituto di Antropologia, 1665.

FERREIRA, Alatéia. Cybermarketing e a Moda: segmentação através dos Blogs e Orkut. Colóquio de Moda. III Colóquio de Moda, Belo Horizonte, 2007.

FERREIRA, Sueli Mara Soares Pinto. Novos paradigmas e novos usuários da informação. Ciência da Informação - Vol 25, número 2, 1995.

GILLMOR, Dan. Nós, os Media. Lisboa: Ed. Editorial Presença, 2005.

HANSEN, Cynthia. BEHLING, Hans Peder. Desfiles de Moda na Era da Informação: Reflexões sobre o Potencial do Desfile enquanto Ferramenta de Comunicação. Intercon Sul 2010: Perspectivas da Pesquisa em Comunicação Digital. p.260 - 294

HINERASKY, Daniela Aline. Jornalismo de Moda: questionamentos da cena brasileira. Congresso Brasileiro de Ciências da Comunicação. XXIX INTERCOM 2006, 06 a 09 de setembro de 2006. Brasília.

LEMOS, Cristina. Inovação na Era do Conhecimento in LASTRES, HelenaM. M., ALBAGLI, Sarita (org). Informação e globalização na era do conhecimento. Rio de Janeiro: Campus, 1999. pp.122-144

LIMEIRA, Tânia. E-marketing: o marketing na internet com casos brasileiros. São Paulo: Saraiva, 2003.

LIPOVETSKY, Gilles. O império do efêmero: a moda e seu destino nas sociedades modernas. São Paulo: Companhia das Letras, 1989.

MELO, José Marques de. Teoria da comunicação: paradigmas latino-americanos. Petrópolis, RJ: Vozes, 1998.

McLUHAN, H. FIORE, Q. The Medium is the Message: An Inventory of Effects. New York: Bantam Books, 1967.

ORLANDI, Letícia. Papo de Mulher: Um Estudo Sobre os Blogs de Moda e Estilo. Intercom - Sociedade Brasileira de Estudos Interdisciplinares da Comunicação XV Congresso de Ciências da Comunicação na Região Sudeste, 13 a 15 de maio de 2010. Vitória

VERGARA, Sylvia C. Projetos e relatórios de pesquisa em administração. São Paulo: Atlas, 2006. 
WERTHEIN, Jorge. A sociedade da informação e seus desafios. Ciência da Informação. Brasília, v. 29, n. 2, maio/ago. 2000.

Texto recebido em 27/08/2013.

Texto aprovado em 29/11/2013. 